\title{
Leer la biblioteca mattelartiana
}

\section{Ler a biblioteca Mattelartiana}

\author{
Raúl Fuentes $\mathrm{Navarro}$ \\ Universidad de Guadalajara, Departamento de Estudios de la Comunicación Social; Universidad \\ Jesuita de Guadalajara, Departamento de Estudios Socioculturales. Guadalajara - Jalisco, México
}

\section{RESUMEN}

El propósito de este artículo es aportar un ángulo de análisis poco desarrollado y aprovechado en los estudios de comunicación en América Latina, a propósito de la reconstrucción de la influencia de la obra de Armand Mattelart en este campo, extendida durante más de cincuenta años. Los recuentos de citas, facilitados por los recursos digitales disponibles en la actualidad, se han desarrollado desde hace décadas en diversos ámbitos científicos como indicadores de influencia y reconocimiento, que no obstante, es necesario contextualizar con cautela.

PALABRAS CLAVE: Bibliografía, análisis de citas, América Latina, comunicación, Armand Mattelart

\section{RESUMO:}

O objetivo deste artigo é apresentar uma perspectiva de análise menos desenvolvida e empregada do que outras sobre os estudos da comunicação na América Latina, em particular pretende-se reconstituir a influência da obra de Armand Mattelart neste campo, prolongada por mais de cinquenta anos. As recontagens de citações, hoje facilitadas pelos recursos digitais disponíveis, se desenvolveram durante décadas em vários campos científicos como indicadores de influência e reconhecimento, que, no entanto, precisam ser contextualizados com cautela.

PALAVRAS-CHAVE: Bibliografia, análise de citações, América Latina , comunicação, Armand Mattelart

\author{
a Profesor-investigador \\ titular del Departamento de \\ Estudios de la Comunicación \\ Social de la Universidad de \\ Guadalajara y Profesor Emérito \\ del ITESO (Universidad \\ Jesuita de Guadalajara). \\ Miembro del Sistema Nacional \\ de Investigadores (Nivel 3) y \\ de la Academia Mexicana de \\ Ciencias. Orcid: https://orcid. \\ org/0000-0001-6494-8122. \\ E-mail:raul@iteso.mx
}


ONVIENE COMENZAR ESTE artículo con una anécdota personal. A mediados de los años 1990, en una de tantas visitas académicas de Armand Mattelart a México, me acerqué a saludarlo después de su conferencia. Entre una pequeña multitud, una joven estudiante de comunicación con actitud de reportera de espectáculos en ciernes apuntó su grabadora al rostro de Mattelart y disparó su pregunta: "Maestro, ¿y qué opina ahora del Pato Donald?". Con su peculiar sonrisa e inconfundible acento en español, la rápida respuesta fue implacable: "Mire: ese libro tiene ya más de veintiún años, por lo tanto es mayor de edad y debe defenderse por sí mismo."

Probablemente esa era una respuesta preconcebida para atender con humor las innumerables impertinencias a las que su fama lo exponía en todas partes, especialmente con respecto al libro al que debía su celebridad, pero como testigo ocasional esa expresión me hizo apreciar más la agudeza excepcional de Mattelart ${ }^{1}$. Y me permite ahora, un cuarto de siglo después de aquel episodio y a casi 50 años de haber leído el primer libro de su autoría que llegó a mis manos, precisamente Para Leer al Pato Donald (1972), proponer un tipo de análisis relativamente poco explorado de su influencia en el campo de la comunicación, compartida como tantas otras cosas con su compañera Michèle².

Tal análisis, centrado en la circulación de sus libros y la acumulación de citas como indicadores de influencia, no podrá profundizarse más por ahora, pero el propósito de este artículo es exponer un acercamiento a su justificación y fundamentación metodológica, que pueda ser discutido y apropiado para articularlo con los otros muchos aportes ya disponibles. Se trata de "cartografiar" lo más sistemáticamente que sea posible el conjunto de una extensa obra bibliográfica que abarca más de cinco décadas y que circula mundialmente en varios idiomas, sobre la cual el propio Mattelart (2013) ha expuesto ya una detallada "cartografía" en diálogo con Michel Sénécal. La premisa fundamental de la propuesta es que la influencia de Mattelart en el campo (teórico, político, académico, ideológico) de la comunicación tiene una dimensión industrialeditorial que es al mismo tiempo una de sus principales manifestaciones

\footnotetext{
${ }^{1}$ Comparto, y probablemente también Mattelart, la interpretación del colega argentino Mariano Zarowsky al respecto: "Es habitual encontrar en la bibliografía crítica latinoamericana un sobredimensionamiento de aspectos parciales y situados de su obra -en especial de sus posiciones de los años 1970 y alrededor del libro sobre las historietas de Disney- que suelen convertir por omisión la parte en un todo. Lo paradójico es que un trabajo que se proponía desmitificar la historieta más popular del momento devino, a partir de ciertas lecturas textualistas y ahistóricas, un nuevo mito" (Zarowsky, 2013, p. 22).

2 Doce de los 47 libros (25\%) incluidos en este análisis están firmados por Armand y Michèle Mattelart, y en algunos casos con alguien más. Pero Michèle tiene también libros de su autoría independiente, que en este análisis no se incluyen porque merecen un análisis específico, no supeditado al de la obra común.
} 
y soportes ${ }^{3}$, y que, siguiendo por cierto el ejemplo mattelartiano, es necesario reconocer, documentar, contextualizar y analizar críticamente, aunque en este artículo no pueda avanzarse todavía demasiado.

El estudio de la comunicación pública de la ciencia es un campo altamente especializado de investigación, dentro del cual los análisis empíricos de las estructuras y procesos de producción, distribución y uso de las publicaciones (libros y revistas) aportan información esencial sobre la formación y desarrollo de las "comunidades científicas" (Crane, 1972; Kuhn, 1962). Si el conocimiento científico es un producto sociocultural, cuya especificidad está, sobre todo, en las reglas que norman su reconocimiento por la comunidad de especialistas, y su legitimidad en la capacidad de esta comunidad para demostrar a otros grupos sociales su sentido de utilidad, puede hacerse una transposición estratégica a los modelos de campo y habitus como Bourdieu (2000), pero podría también analizarse la producción, circulación y apropiación sociales del conocimiento científico con base en modelos de comunicación (Fuentes, 2018), especialmente los orientados desde la (crítica de la) economía política, como los de Mattelart, para lo cual es necesario contar con bases de información descriptiva, que para este artículo son muy limitadas.

En otros términos, por ahora la pregunta básica es: ¿cómo "se defienden" a sí mismos los libros de Mattelart? O mejor, ¿¿cómo esos libros han extendido la influencia de los aportes expresados en ellos, precisa y primordialmente sobre los lectores y la institución académica en que se ubican? El sentido básico de estas preguntas no puede ser sino una apropiación de una sentencia famosa de Umberto Eco (1983/1992), en El Nombre de la Rosa: "El bien de un libro consiste en ser leído. Un libro está hecho de signos que hablan de otros signos, que, a su vez, hablan de las cosas. Sin unos ojos que lo lean, un libro contiene signos que no producen conceptos. Y, por tanto, es mudo" (p. 374).

\section{LA PERSISTENCIA DE UNA PRESENCIA INFLUYENTE POR MÁS DE CINCO DÉCADAS}

De acuerdo con varias fuentes documentales fácilmente accesibles (Constantinou, 2008; del Valle Rojas, 2013; Infoamerica, s.d.; Maldonado \& León-Castro, 2019; Mattelart, 2013; Zarowsky, 2013), Armand Mattelart,

\footnotetext{
3 El libro académico y la industria que lo produce y distribuye han sido objeto de investigación desde diversos ángulos, aunque no son un sector tan explorado como otros en el campo de la "producción cultural restringida" (Bourdieu, 1993). Probablemente el estudio de Thompson (2005) sobre la transformación del sector en la "Era Digital" siga teniendo mucha utilidad para comprender la estructuración de ese campo, y ciertos estudios más recientes aportan pistas importantes para seguir analizando la compleja relación entre la academia y la industria editorial, por ejemplo, Cruz-Quintana (2019), Fyfe et al. (2017), Giménez-Toledo et al. (2019), Kulczycki et al. (2018) y Tejada-Artigas et al. (2020).
} 
nacido en Bélgica en 1936, estudió derecho, ciencia política y demografía en Lovaina y en París, donde conoció a la francesa Michèle en 1962. Desde ese año, y por once más, vivió, enseñó y trabajó en la Universidad Católica de Chile, específicamente en proyectos de la Unesco sobre población y desarrollo, y en el Centro de Estudios de la Realidad Nacional (Ceren), que contribuyó a crear. Por su vinculación con el régimen presidido por Salvador Allende, debió salir apresuradamente del país a raíz del golpe de estado militar del 11 de septiembre de 1973, terminando así, abruptamente, una primera etapa, la directamente latinoamericana, de su carrera.

Una segunda etapa estuvo caracterizada por la inestabilidad laboral como profesor de la Universidad de París (VII y VIII) y una diversidad de experiencias internacionales y encargos institucionales, y consumió los diez años siguientes hasta desembocar en 1983 en la obtención de una plaza como profesor del Departamento de Comunicaciones de la Universidad de Rennes 2 en la Alta Bretaña, donde permaneció hasta 1997, cuando pasó a la cátedra en París 8 (Vincennes-Saint Denis). La experiencia chilena se amplió entonces al análisis de casos de otros países y situaciones (Mozambique, Nicaragua en los años 80), y especialmente a la denuncia del imperialismo cultural y la acción de las empresas transnacionales, para consolidar una perspectiva propia de la (crítica de la) economía política a partir de la Conferencia Internacional sobre el Imperialismo Cultural, celebrada en Argel en 1977 (Mattelart, 1978). Exiliado en Francia, Mattelart se ubicó al principio como un intelectual heterodoxo y algo marginal, "en un mundo intelectual y académico donde los estudios en comunicación ni se hallaban demasiado desarrollados más allá de su versión semiológica, ni ... gozaban de mucho prestigio institucional frente a la sociología o las ciencias humanas tradicionales" (Zarowsky, 2013, p. 27).

Una vez establecido plenamente como profesor, se inició en 1983 una tercera etapa de la trayectoria mattelartiana, en la que, sobre todo a partir de la publicación de Pensar Sobre los Medios, Comunicación y Crítica Social (Mattelart \& Mattelart, 1987), los aportes epistemológicos e históricos críticos impulsaron el desarrollo de una obra madura y singular, que ha hecho "fluir procesos de circulación internacional de las ideas" de la periferia hacia el centro, esbozando un perfil "latinoamericanizado", caracterizado por "la apertura, el cosmopolitismo y la permanente tensión hacia la política" (Zarowsky, 2013, p. 38). El propio Mattelart considera este libro como una obra bisagra:

Su punto de partida es una reflexión sobre cómo y por qué el ámbito sociocultural francés ha tardado tanto en investigar sobre los medios de comunicación. Y cuando lo ha hecho, por qué ha persistido el contraste entre la multiplicación de 
análisis discursivos y el olvido de la economía, de la historia y de lo internacional. Pero esta es solo una de las cuestiones de partida, porque el libro está en sintonía con un espíritu del tiempo crítico. Tanto es así que desde los primeros años de los 1980, tanto en Europa como en los Estados Unidos y en Latinoamérica, se está planteando la cuestión del cambio de paradigmas que hasta entonces presidían las ciencias sociales. Y, a través de dicho cambio, la cuestión que está en juego es la transformación de las categorías de análisis que hasta entonces habían contribuido a pensar el cambio social mismo, así como las estrategias de sus actores. Se trata, por tanto, de un momento en el que se realizan balances y prospectivas; y las ciencias de la información y de la comunicación son parte interesada en las controversias. (Mattelart, 2013, p. 155)

Si bien podría identificarse una cuarta etapa de la trayectoria de Mattelart a partir del año 2000, se ha decidido considerar estos últimos veinte años como una "extensión" de la tercera etapa de su producción intelectual, como una profundización de su influencia en el campo de estudios de la comunicación, y una ocasión de multiplicar los reconocimientos, a partir de su nombramiento como Profesor Emérito de la Universidad de Paris 8 (Vincennes-Saint-Denis) y del otorgamiento solemne de Doctorados Honoris Causa: Universidad Autónoma de Nuevo León (México, 2007); Universidad Nacional de Córdoba (Argentina, 2011); Universidad de Málaga (España, 2014); Universidad de La Habana (Cuba, 2015); Universidad de Valladolid (España, 2016); además de la creación en 2015 de la Cátedra Armand Mattelart de Economía y Políticas de Comunicación, en el Centro Internacional de Estudios Superiores en Comunicación para América Latina (Ciespal), en Ecuador, que ha sido dirigida desde su origen por Alberto Efendy Maldonado Gómez de la Torre.

Tres o cuatro "etapas" representan de cualquier manera una categorización muy fácilmente relativizable, pues los flujos de experiencia individual y colectiva que pretenden organizar son siempre más complejos y multivalentes que las etiquetas usadas para enfatizar cambios y permanencias. No obstante, conservan algún grado de utilidad para analizar fenómenos de alcance geográfico muy amplio y temporal bastante extenso, desde el punto de vista, al menos, de la biografía, aunque no es ese, sino la bibliografía, el foco central de este artículo.

\section{LA INFLUENCIA CONSTITUTIVA DE MATTELART RECONOCIDA DESDE AQUÍ Y DESDE ALLÁ}

En 1989, el académico mexicano Carlos Gómez-Palacio (1945-2016) presentó como tesis doctoral en la Universidad Stanford el "primer intento 
de análisis de los orígenes, desarrollo y estado actual de la investigación de la comunicación en América Latina basado en datos empíricos" (GómezPalacio, 1989, p. 2). El proyecto, dirigido por Steven H. Chaffee (1935-2001), tuvo el propósito de identificar "1) los factores determinantes de los tipos de estudios que emergieron en la región; 2) los principales temas de investigación; 3) los autores más influyentes; y 4) las principales corrientes de influencia teórica sobre los investigadores latinoamericanos" (Gómez-Palacio, 1989, p. 3), explorando sus cambios a lo largo del tiempo. El diseño metodológico abarcó tres niveles analíticos: en el primer, análisis de contenido de artículos publicados en diez revistas académicas latinoamericanas y siete estadounidenses; en el segundo nivel, análisis de citación entre autores y entre las revistas latinoamericanas; y en el tercer, sondeo mediante entrevistas con 50 académicos latinoamericanos y 51 estadounidenses con experiencia sobre América Latina.

La tesis de Gómez-Palacio permanece inédita como tal, aunque algunos de sus resultados fueron difundidos en un artículo célebre (Chaffee et al., 1990)4, y pese a que puede reconocerse como un estudio cuantitativo metodológicamente "ejemplar" (Fuentes, 2019). Entre los resultados se destacan los "mapas" construidos con los proyectos más importantes de investigación desarrollados en América Latina en dos periodos temporales precisos: 1960-1976 y 1977-1984, así como la identificación de los "investigadores más influyentes": Armand Mattelart y su grupo en Chile; Antonio Pasquali en Venezuela; Luis Ramiro Beltrán en Colombia; Eliseo Verón en Argentina; Paulo Freire en Brasil y Chile; en ese orden. Otros investigadores influyentes, que en algún sentido podrían compartir con los primeros el apelativo de "padres (y madres) fundadores", según la expresión de Schwarz y Jaramillo (1986), son José Marques de Melo en Brasil; Javier Esteinou Madrid, Fátima Fernández Christlieb y Fernando Reyes Matta en México; Jesús Martín-Barbero en Colombia (Gómez-Palacio, 1989, p. 132).

Pero, con mucha diferencia en la tesis de Gómez-Palacio, Mattelart resultó ser el "autor más influyente" en cuanto a la investigación de la comunicación en América Latina, pues "no solo ha sido el autor más citado, independientemente del tiempo, el tema o la revista, sino que fundó además él mismo dos importantes revistas (Cuadernos de la Realidad Nacional y Comunicación y Cultura)" (Gómez-Palacio, 1989, p. 147). Se le registraron 154 citas en 451 artículos en las revistas latinoamericanas seleccionadas para el análisis. Y "esta preeminencia de Mattelart sobre los demás autores en el campo" se manifestó también en que

\footnotetext{
${ }^{4}$ Google Scholar registra nueve citas a la tesis, seis de las cuales corresponden a publicaciones de Raúl Fuentes Navarro, a quien Gómez-Palacio le proporcionó una copia en 1993. El artículo es "célebre" por la calidad y no necesariamente la cantidad de citas, pues la misma fuente registra solo treinta: una en alemán, seis en portugués, dos en español y el resto en inglés (consulta el 22 de septiembre de 2020).
} 
él fue el autor más citado "en cada una de las etapas de desarrollo de la disciplina en la región, así como en cada grupo de revistas considerado" (p. 147), las de Sudamérica hispánica (38), las de México (86) y las de Brasil (30).

Además de las 154 citas a Armand Mattelart (28 entre 1960 y 1976 y 126 entre 1977 y 1986), Michèle Mattelart aparece también, con 48 citas, entre los 15 autores más citados; de hecho, la única autora mujer en la lista (con 18 en el primer periodo y 30 en el segundo) (Gómez-Palacio, 1989, p. 126). Y aunque Gómez-Palacio no lo desglosa textualmente, sí registra, en el cuadro respectivo, la distribución de las citas de Michèle Mattelart: 43 en español y 5 en francés, sin aparecer en portugués ni en inglés (Gómez-Palacio, 1989, p. 129). Finalmente, el análisis muestra que Mattelart "fue citado básicamente en español":

El 83\% de sus citas refieren a la versión en español de sus libros o de sus artículos. Esta es la única área de análisis en que la influencia de Mattelart no es tan fuerte. En cuanto a citas en portugués, por ejemplo, ocupa el tercer puerto después de Marques de Melo y de Freire, dos investigadores brasileños que parecen ser muy influyentes en su país de origen; en el grupo de citas en francés, Mattelart comparte el cuarto lugar con Greimas, Morin y Verón, después de Barthes, Gramsci y Metz. Por último, en las citas en inglés la presencia de [Armand] Mattelart es prácticamente nula. (Gómez-Palacio, 1989, p. 127)

Por otra parte, en las entrevistas a los investigadores se incluyeron dos preguntas acerca de los "autores más influyentes" en el campo de la investigación en América Latina y sobre ellos mismos como investigadores. Aunque las preguntas fueron abiertas, "hubo un grupo de aproximadamente diez autores muy mencionados, y nuevamente Mattelart resultó ser el investigador más influyente: el 71\% de los informantes latinoamericanos lo nombraron como el más influyente para la región y el $24 \%$ para la actividad profesional personal". Completaron la decena de influencias mayormente reconocidas para la región Antonio Pasquali, Luis Ramiro Beltrán, José Marques de Melo, Eliseo Verón, Javier Esteinou Madrid, Fernando Reyes Matta, Paulo Freire, Jesús MartínBarbero y Fátima Fernández Christlieb (Gómez-Palacio, 1989, p. 130). Los datos del análisis de citas y de las respuestas a la encuesta resaltan que Mattelart es el único autor cuyo nombre se menciona entre los más influyentes en todas las diez categorías temáticas, en cinco de ellas como el primer lugar ("Comunicación y Desarrollo", "Comunicación y Cultura", "Características de los Medios Latinoamericanos", "Historia de la Comunicación en América Latina" y "Políticas de Comunicación"); Michèle aparece, por su cuenta, en seis de las categorías (Gómez-Palacio, 1989, p. 128). 
Una de las conclusiones más interesantes de la tesis de Gómez-Palacio es que "mientras que para los investigadores latinoamericanos los orígenes de la disciplina se pueden atribuir a factores externos, la producción investigativa, o al menos la que ellos reconocen como más importante, ha sido latinoamericana" y marcadamente crítica (Gómez-Palacio, 1989, p. 166), si bien "este estudio sugiere que no podemos hablar de un modelo latinoamericano de investigación. Más aún, sugiere que no existe una comunidad bien integrada de investigadores latinoamericanos de la comunicación", y puede hipotetizarse que "los investigadores latinoamericanos se perciben desconectados del resto de la comunidad académica: sus preocupaciones e intereses de investigación se enfocan en sus propios países y están determinados por la situación política y económica nacional en un determinado momento" (Gómez-Palacio, 1989, p. 176). La falta de integración regional y los cambios previsibles por la "globalización", o "mundialización" en precisión mattelartiana, ya en marcha en 1985, dejaban abiertas muchas preguntas sobre el futuro del campo, que incansablemente Mattelart se ha encargado, como otros, de profundizar, precisar, debatir, polemizar, reformular.

\section{RECUENTO DE PUBLICACIONES Y CITAS EN TRES ETAPAS DE LA TRAYECTORIA DE MATTELART}

Según las etapas que se distinguen con cierta facilidad tanto desde una cronología elemental de la trayectoria de Mattelart como del análisis de GómezPalacio sobre las influencias reconocidas por investigadores estadounidenses y latinoamericanos en la investigación de América Latina, es indudablemente central el golpe de Estado de 1973 en Chile. La primera de las etapas, correspondiente al "laboratorio chileno" según la atinada expresión de Zarowsky (2013), permite reconstruir el proceso de conversión de Mattelart de un demógrafo a un estudioso de los medios como vehículos transmisores de ideología. La segunda etapa, que se ubica entre 1974 y 1986, como es bastante obvio, tiene otras condiciones y representa una transición difícil pero contundente de Mattelart como líder de la "corriente crítica" de la investigación latinoamericana de los medios de comunicación, con rasgos más cercanos en ocasiones al activismo militante y "denuncista" que a la academia. Finalmente, mediante un esfuerzo sostenido y articulado de reflexión epistemológica, teórica y metodológica también muy crítica, la tercera etapa de la trayectoria, formulada desde 1986 hasta la actualidad, se caracteriza no solo por la consolidación de un liderazgo de alcance mundial, sino por la influencia propiamente académica de su obra.

En términos numéricos, el Cuadro 1 sintetiza los resultados del análisis de la bibliografía de Mattelart a lo largo de las tres etapas de su trayectoria y las 
citas recuperadas en cada una de ellas, según el idioma de las ediciones citadas. Conviene señalar que para el presente análisis se ha hecho un uso intensivo, pero no "lineal" de la documentación digital canalizada mediante Google Scholar, llamado en español "Google Académico" (https://scholar.google.com), un "buscador" especializado que fue lanzado a fines de 2004 y que se ha vuelto indispensable como fuente de referencias académicas. Para este estudio se ha complementado la información descriptiva disponible en este sitio con la organizada en otros, como la librería digital Amazon (https://www.amazon.com) y las redes sociodigitales ResearchGate (https://www.researchgate.net/) y Academia (https://www.academia.edu/), además de la bibliografía expuesta en Por una Mirada-mundo: Conversaciones con Michel Sénécal (Mattelart, 2013). Cabe advertir, como lo han hecho Kulczycki et al. (2018), que "en la mayoría de los países [europeos, incluidos en su estudio], menos del 50\% de las publicaciones de las ciencias sociales y humanidades, son visibles en el Web of Science" (p. 484) o Scopus, las bases de datos consideradas internacionalmente como las de mayor prestigio y calidad, por lo tanto las que tienden a utilizarse predominantemente para la evaluación, debido a que en los países donde el inglés no es la lengua oficial, los patrones de publicación en estas áreas tienen que ver no solo con las diferencias entre disciplinas, sino también con los legados históricos y culturales de cada país.

Cuadro 1. Libros publicados y citas recuperadas por Google Scholar, según la etapa en la trayectoria de Mattelart y el idioma de edición

\begin{tabular}{ccccccc} 
Etapa (años) & Libros & $\begin{array}{c}\text { Citas a eds. } \\
\text { en francés }\end{array}$ & $\begin{array}{c}\text { Citas a eds. } \\
\text { en español }\end{array}$ & $\begin{array}{c}\text { Citas a eds. } \\
\text { en inglés }\end{array}$ & $\begin{array}{c}\text { Citas a eds. } \\
\text { en portugués }\end{array}$ & $\begin{array}{c}\text { Citas } \\
\text { totales }\end{array}$ \\
\hline$(1964-1973)$ & 14 & 16 & 1.711 & 1.015 & 199 & $2.941+$ \\
$(1974-19 S 5)$ & 16 & $51 S$ & 620 & 1.414 & 77 & $2.629+$ \\
\hline$(19 S 6-2014)$ & 17 & 3.144 & 5.593 & 2.969 & $3.7 S 1$ & $15.4 S 7+$ \\
Totales & 47 & $3.67 S$ & 7.924 & $5.39 S$ & 4.057 & $21.057+$
\end{tabular}

Acerca de los idiomas, el propio Mattelart ha dado una detallada explicación de sus estrategias y las condiciones diversas de difusión de su obra:

Todas mis obras publicadas en francés han sido traducidas al español. Pero, si mi bibliografía en esta lengua es más larga que la lista de obras en francés, es porque debemos añadir los libros publicados en Chile, en México o en Argentina, mientras residía en Santiago, y que jamás han sido traducidos al francés, con la sola excepción

\footnotetext{
${ }^{5}$ Un análisis bibliométrico más completo, no abordado en este artículo, debería de considerar críticamente las diferencias en los patrones de citación detectadas sobre las bases (de acceso abierto) aquí utilizadas y las prestigiadas por la "industria académica", como Web of Science o Scopus (de acceso restringido).
} 
del libro sobre la ideología de los comics de Disney. En lo que respecta al inglés, salvo cuatro excepciones, todas las obras publicadas en francés han sido traducidas a esta lengua. Únicamente tres libros existen solo en inglés: el informe redactado, bajo demanda, de las Naciones Unidas, y publicado con el título Transnationals and the Third World (1983); los dos volúmenes de la antología Communication and Class Struggle (1979 y 1983), en colaboración con Seth Siegelaub, y otra compilación, Communication in Popular Nicaragua (1985). El primero jamás ha sido publicado en francés, porque primero tuve que esperar a tener la autorización del comanditario, para poder publicarlo en su versión original, en inglés, y después, como me encontraba en la etapa nómada, no me ocupé de su traducción. En cuanto al segundo, que comprende más de ochocientas páginas, en pequeños caracteres, en la época, visto el tema, resultaba poco imaginable encontrar un editor francés que se lanzara a la aventura. Incluso hoy, no es tampoco evidente, dado el tamaño de las traducciones. En cuanto al tercero, debo decir que jamás encontró editor. En contrapartida, todas estas obras han dado lugar a artículos sustanciales en francés o en castellano. Inversamente, los libros publicados en francés, que no han sido traducidos al inglés, también han dado lugar a artículos en esta última lengua. (Mattelart, 2013, p. 191)

En los Cuadros 2, 3 y 4 se detallan, por etapas cronológicas, las obras publicadas y las ediciones traducidas, sea al español, al francés, al inglés o al portugués, así como las citas registradas a las publicaciones en cada idioma, aunque se registran también, en su caso, las traducciones de algunos libros a otras lenguas, además de esas cuatro.

Como se indica en el Cuadro 1, en el total hay más citas en español, inglés y portugués que en francés, si bien probablemente eso se deba al método de recolección de los datos, pues la mayor parte de las obras fueron publicadas originalmente en francés. También es claro que más del 70\% de las 21.057 citas corresponden a las publicaciones de la tercera etapa, indicador muy fuerte del crecimiento de la presencia de Mattelart en el campo, aunque probablemente ese dato también haya sido afectado por el desarrollo "exponencial" de los recursos digitales disponibles, durante los últimos veinte años. Esas y otras "reservas" en la interpretación son indispensables para contextualizar adecuadamente los resultados obtenidos por este método ${ }^{6}$, y no podrán resolverse aquí.

\footnotetext{
${ }^{6}$ Las consultas en español a Google Scholar se realizaron en Guadalajara, México, hasta el 01/09/2020. Puede suponerse, aunque no se constató, que las consultas desde otro lugar, otro periodo temporal o en otro idioma, hubieran producido alguna variación en los resultados entregados por el sitio, pues cada vez más refinadamente los algoritmos que producen las respuestas a las consultas incorporan interpretaciones automáticas del "perfil" del usuario.
} 
Cuadro 2. Referencias de libros y ediciones de Armand Mattelart publicados en la "primera etapa" de su trayectoria, y las citas registradas en Google Scholar

\begin{tabular}{|c|c|c|}
\hline Título, edición, editorial, año de publicación & $\begin{array}{l}\text { Citas por } \\
\text { idioma }\end{array}$ & $\begin{array}{l}\text { Suma } \\
\text { citas }\end{array}$ \\
\hline $\begin{array}{l}\text { Manual de Análisis Demográfico (Escuela de Sociología U. Católica de } \\
\text { Chile, Santiago, 1964) }\end{array}$ & 23 & 23 \\
\hline $\begin{array}{l}\text { La Problématique du Peuplement Latino-américain (c/ M. Mattelart, } \\
\text { Éditions Universitaires, Paris, 1964) }\end{array}$ & 4 & 7 \\
\hline $\begin{array}{l}\text { *La Problemática de la Población Latinoamericana (c/ M. Mattelart, } \\
\text { Premiá, México, 19\$2) }\end{array}$ & 3 & \\
\hline Atlas Social de las Comunas de Chile (E. del Pacífico, Santiago, 1965) & 30 & 30 \\
\hline $\begin{array}{l}\text { Integración Nacional y Marginalidad: Un Ensayo de Regionalización Social } \\
\text { de Chile (c/ M. A. Garretón, E. del Pacífico, Santiago, 1965) }\end{array}$ & 41 & 41 \\
\hline Géopolitique du Contrôle des Naissances (Éditions Universitaires, Paris, 1967) & 7 & 12 \\
\hline * ¿Adónde va el control de la natalidad? (U. de Chile, Santiago, 1967) & 5 & \\
\hline $\begin{array}{l}\text { La Mujer Chilena en una Nueva Sociedad (c/ M. Mattelart, E. del Pacífico, } \\
\text { Santiago, 196S) }\end{array}$ & 56 & 56 \\
\hline $\begin{array}{l}\text { La Vivienda y los Servicios Comunitarios Rurales. Una metodología de } \\
\text { programación (c/ R. Eyheralde, A. Peña y A. Necochea, ICIRA, Santiago, 196S) }\end{array}$ & 3 & 3 \\
\hline $\begin{array}{l}\text { Juventud Chilena: Rebeldía y Conformismo (c/ M. Mattelart, U. de Chile, } \\
\text { Santiago, 1970) }\end{array}$ & 60 & 60 \\
\hline $\begin{array}{l}\text { Los Medios de Comunicación de Masas; La Ideología de la Prensa Liberal en } \\
\text { Chile (c/ M. Mattelart y M. Piccini, Cuadernos del Ceren (3), Santiago, 1970) }\end{array}$ & 71 & 71 \\
\hline $\begin{array}{l}\text { La Ideología de la Dominación en una Sociedad Dependiente (c/ C. Castillo } \\
\text { y L. Castillo, Signos, Buenos Aires, 1970) }\end{array}$ & 57 & 57 \\
\hline $\begin{array}{l}\text { Comunicación Masiva y Revolución Socialista (c/ P. Biedma y S. Funes, } \\
\text { Prensa Latinoamericana, Santiago, Diógenes, México, 1971) }\end{array}$ & 35 & 35 \\
\hline $\begin{array}{l}\text { Para Leer al Pato Donald: (Comunicación de Masa y Colonialismo) (c/ A. } \\
\text { Dorfman, Ed. Universitarias, Valparaíso,1971; Siglo XXI, Buenos Aires, } \\
\text { México, 1973) }\end{array}$ & 1.022 & $2.241+$ \\
\hline $\begin{array}{l}\text { *How to Read Donald Duck: Imperialist Ideology in the Disney Comic } \\
\text { (c/ A. Dorfman, International General, 1975) }\end{array}$ & 1.015 & \\
\hline $\begin{array}{l}\text { *Donald L'imposteur ou L'impérialisme Raconté aux Enfants } \\
\text { (c/ A. Dorfman, Alain Moreau, Paris, 1977) }\end{array}$ & 5 & \\
\hline $\begin{array}{l}\text { *Para Ler o Pato Donald: Comunicação de Massa e Colonialismo } \\
\text { (c/ A. Dorfman, Paz e Terra, Rio de Janeiro, 1977) }\end{array}$ & 199 & \\
\hline $\begin{array}{l}\text { *(Traducciones también al alemán, coreano, danés, finlandés, griego, } \\
\text { italiano, japonés, neerlandés, esloveno, turco, etc.) }\end{array}$ & + & \\
\hline $\begin{array}{l}\text { Agresión Desde el Espacio: Cultura y Napalm en la Era de los Satélites (Tercer } \\
\text { Mundo, Santiago, 1972; Siglo XXI, Buenos Aires, México, España, 1973) }\end{array}$ & 111 & 111 \\
\hline $\begin{array}{l}\text { La Comunicación Masiva en el Proceso de Liberación (Siglo XXI, } \\
\text { Buenos Aires, México, España, 1973) }\end{array}$ & 194 & 194 \\
\hline$E=1.711|F=16| I=1.015 \mid P=199$ & & 2.0 \\
\hline
\end{tabular}

Mariano Zarowsky (2013), autor de la muy sólida y crítica tesis doctoral sobre la obra de Mattelart, advierte dos factores contextuales: "el desarrollo destacado de las ciencias sociales en Chile", y la "novedad y centralidad del debate sobre 
la cultura y la comunicación en la transición socialista", como centrales para "comprender la génesis de la reflexión de Mattelart y su aporte al pensamiento sobre la comunicación" en los años 1960 y 1970. Mattelart fue "un enérgico participante de los debates político-culturales de la izquierda chilena y un activo colaborador de algunas de sus experiencias" (Zarowsky, 2013, p. 24). Para Leer al Pato Donald (Mattelart y Dorfman, 1972) es un producto paradójico de ese contexto, que "rápidamente se convirtió en un best-seller y en una suerte de manual de descolonización cultural para el continente", pero "haciendo abstracción de sus precisas condiciones de emergencia, una lectura del libro que lo fue despojando de su contexto de interlocución, extendió a sus autores cierta imagen estereotipada del intelectual politizado latinoamericano del periodo" (Zarowsky, 2013, p. 21).

Desde el punto de vista del análisis de citas de este trabajo, es notable la persistencia de esa "imagen" casi cincuenta años después. El 76\% de las citas recuperadas en 2020 a las publicaciones de esta primera etapa de la producción editorial de Mattelart corresponden a ese libro, reeditado en múltiples países, idiomas y formatos. Otro estudioso latinoamericano de la obra de Mattelart, Alberto Efendy Maldonado (2019), por su parte, constata que "al estudiar la producción de los autores retrospectivamente, se comprueba que, al inicio, fueron cuestiones ideológicas confrontadas, también, con un discurso ideológico". Después, "vendría la preocupación por caracterizar los sistemas multinacionales de información ... y a partir de 1974, por la problematización sistemática de la categoría cultura". La segunda etapa de la trayectoria mattelartiana estaría entonces orientada, en los años 1980, hacia la reflexión "sobre los modelos, los paradigmas, las concepciones, las genealogías de las redes conceptuales" (pp. 52-53).

Cuadro 3. Referencias de libros y ediciones de Armand Mattelart publicados en la "segunda etapa" de su trayectoria, y las citas registradas en Google Scholar

\begin{tabular}{lcc}
\multicolumn{1}{c}{ Títulos, ediciones, editoriales, años de publicación } & $\begin{array}{c}\text { Citas por } \\
\text { idioma }\end{array}$ & $\begin{array}{c}\text { Suma } \\
\text { citas }\end{array}$ \\
\hline $\begin{array}{l}\text { La Cultura como Empresa Multinacional (Era, México, 1974) } \\
\text { *As Multinacionais da Cultura (Civilização Brasileira, Rio de } \\
\text { Janeiro, 1976) }\end{array}$ & 159 & 194 \\
$\begin{array}{l}\text { Mass Media, Idèologies et Mouvement Rèvolutionnaire, Chili, 1970-1973 } \\
\text { (Anthropos, Paris, 1974) }\end{array}$ & 112 & 154 \\
*Mass Media, Ideologies, and the Revolutionary Movement \\
(Harvester, 19So)
\end{tabular}


Cuadro 3. Continuación

\begin{tabular}{|c|c|c|}
\hline Títulos, ediciones, editoriales, años de publicación & $\begin{array}{l}\text { Citas por } \\
\text { idioma }\end{array}$ & $\begin{array}{l}\text { Suma } \\
\text { citas }\end{array}$ \\
\hline $\begin{array}{l}\text { Multinationales et Systèmes de Communication: Les Appareils } \\
\text { Ideologiques de l'Imperialisme (Anthropos, Paris, 1976) }\end{array}$ & 136 & GSS \\
\hline $\begin{array}{l}\text { *Multinacionais e Sistemas de Comunicação: os Aparelhos } \\
\text { Ideológicos do Imperialismo (São Paulo, Ciências Humanas, 1976) }\end{array}$ & 42 & \\
\hline $\begin{array}{l}\text { *Multinacionales y Sistemas de Comunicación. Los Aparatos } \\
\text { Ideológicos del Imperialismo (Siglo XXI, México, Buenos Aires, } \\
\text { España, 1977) }\end{array}$ & $S_{5}$ & \\
\hline $\begin{array}{l}\text { *Multinational Corporations and the Control of Culture: The } \\
\text { Ideological Apparatuses of Imperialism (Harvester, 1979) }\end{array}$ & 425 & \\
\hline $\begin{array}{l}\text { Frentes Culturales y Movilización de Masas (c/ M. Mattelart, } \\
\text { Anagrama, Barcelona, 1977) }\end{array}$ & 29 & 29 \\
\hline $\begin{array}{l}\text { Comunicación e Ideologías de la Seguridad (c/ M. Mattelart, } \\
\text { Anagrama, Barcelona, 197\$) }\end{array}$ & 31 & 31 \\
\hline $\begin{array}{l}\text { De L'usage des Medias en Temps de Crise. Les Nouveaux Profils des } \\
\text { Industries de la Culture (c/ M. Mattelart, Alain Moureau, Paris, 1979) }\end{array}$ & 39 & GS \\
\hline $\begin{array}{l}\text { *Los Medios de Comunicación en Tiempos de Crisis (c/ M. } \\
\text { Mattelart, Siglo XXI, México, 19S1) }\end{array}$ & 29 & \\
\hline $\begin{array}{l}\text { Communication and Class Struggle, An Anthology. Vol, 1: Capitalism, } \\
\text { Imperialism (1979), Vol. 2: Liberation, Socialism (19So), (c/ S. } \\
\text { Siegelaub, International General Editions.) }\end{array}$ & $196+50$ & $246+$ \\
\hline $\begin{array}{l}\text { *Comunicación y Lucha de Clases. Vol 1. Capitalismo (c/ S. } \\
\text { Siegelaub, Ciespal, Quito, 2017). }\end{array}$ & + & \\
\hline $\begin{array}{l}\text { Télévision, Enjeux sans Frontières: Industries Culturelles et Politique } \\
\text { de la Communication (c/ J. M. Piemme, Presses Universitaires de } \\
\text { Grenoble, 19So) }\end{array}$ & 43 & 43 \\
\hline $\begin{array}{l}\text { La Televisión Alternativa (c/ J. M. Piemme, Anagrama, Barcelona, } \\
\text { 19S1) }\end{array}$ & 59 & 59 \\
\hline Comunicación y Nueva Hegemonía (Celadec-CEDEE, Lima, 19\$1) & 32 & 32 \\
\hline $\begin{array}{l}\text { Comunicación y Transición al Socialismo. El Caso Mozambique } \\
\text { (Editor), (Era, México, 19S1) }\end{array}$ & S & S \\
\hline $\begin{array}{l}\text { Technologie, Culture et Communication: Rapport Remis à Jean- } \\
\text { Pierre Chevènement, Ministre de la Recherche et de l'industrie (c/ Y. } \\
\text { Stourdzé, La Documentation Française, 19S2) }\end{array}$ & 40 & 115 \\
\hline $\begin{array}{l}\text { *Tecnología, Cultura y Comunicación (c/ Y. Stourdzé, Mitre, } \\
\text { Barcelona, 19S4) }\end{array}$ & 52 & \\
\hline $\begin{array}{l}\text { *Technology, Culture, and Communication: A Report to the French } \\
\text { Minister of Research and Industry (Elsevier Science Ltd., 19S5) }\end{array}$ & 23 & \\
\hline
\end{tabular}




\begin{tabular}{|c|c|c|}
\hline Títulos, ediciones, editoriales, años de publicación & $\begin{array}{l}\text { Citas por } \\
\text { idioma }\end{array}$ & $\begin{array}{l}\text { Suma } \\
\text { citas }\end{array}$ \\
\hline $\begin{array}{l}\text { América Latina en la Encrucijada Telemática (c/H.Schmucler, ILET, } \\
\text { México, } 19 \$_{3} \text {; Paidós, Barcelona). }\end{array}$ & $9 S$ & 221 \\
\hline $\begin{array}{l}\text { *L'ordinateur et le Tiers Monde: L'Amérique Latine à l'heure des } \\
\text { choix télématiques (La Découverte, Paris, } 19 \$_{3} \text { ) }\end{array}$ & $3^{S}$ & \\
\hline $\begin{array}{l}\text { *Communication and Information Technologies: Freedom of Choice } \\
\text { for Latin America? (Ablex Pub., 19\$5) }\end{array}$ & S5 & \\
\hline $\begin{array}{l}\text { Transnationals and the Third World: The Struggle for Culture } \\
\text { (Praeger, } 19 S_{3} \text { ) }\end{array}$ & $2 S_{3}$ & $2 S_{3}$ \\
\hline $\begin{array}{l}\text { La Culture Contre la Démocratie? L'audiovisuel à L’heure } \\
\text { Transnationale (c/ M. Mattelart et X. Delcourt, La Découverte, 19\$4) }\end{array}$ & 110 & $402+$ \\
\hline $\begin{array}{l}\text { ¿La Cultura Contra la Democracia? (c/ M. Mattelart et X. } \\
\text { Delcourt, Mitre, Barcelona, 19\$4) }\end{array}$ & $3 S$ & \\
\hline $\begin{array}{l}\text { *International Image Markets: In Search of an Alternative Perspective } \\
\text { (c/ M. Mattelart et X. Delcourt, National Book Network, 19\$5) }\end{array}$ & 254 & \\
\hline $\begin{array}{l}\text { *A cultura Contra a Democracia? O Audiovisual na Época Transnacional } \\
\text { (c/ M. Mattelart et X. Delcourt, São Paulo, Brasiliense, 19\$7) }\end{array}$ & + & \\
\hline $\begin{array}{l}\text { Communicating in Popular Nicaragua: An Anthology (International } \\
\text { General Editions, NY, 19S6) }\end{array}$ & 56 & 56 \\
\hline$E=620|F=51 S| I=1.414 \mid \mathrm{P}=77$ & & $.629+$ \\
\hline
\end{tabular}

Esta segunda etapa puede considerarse, como ya se ha señalado, una "transición múltiple" que comienza por el exilio, pasa por el "nomadismo" y concluye en la consolidación académica de Mattelart en Francia y, desde ahí, en el mundo. Zarowsky (2013) subraya algunas prácticas notables de Mattelart que contribuyeron en los años 1980 a la "internacionalización" y al paso "de la periferia al centro de su trayectoria académica y política": la dirección de Comunicación y Cultura (1973-1985), con Héctor Schmucler y Hugo Assmann, y "los trabajos de investigación, formación y asesoramiento que realizó en la Mozambique socialista ... y en la Nicaragua sandinista”, entre otras "intervenciones" que "dan testimonio de la existencia en el periodo de redes y espacios de entrecruzamientos múltiples” (p. 28).

Según Maldonado (2019), todo eso contribuyó significativamente a la comprensión del campo de la comunicación en América Latina y en el mundo; de hecho, "por medio de la reflexión sobre las realidades del funcionamiento de los sistemas, los medios, las culturas y las políticas de comunicación, se amplió y profundizó la compresión teórica sobre los procesos históricos concretos de la comunicación social". Pero a falta de 
desarrollo del nivel epistemológico de la investigación, "las categorías, los conceptos, las ideologías, los modelos, las herramientas, eran aplicados por las demandas de la realidad, por el enfrentamiento con la dominación, por la necesidad de denunciar los mecanismos de opresión imperialistas" (pp. 53-54). La atención a esta carencia habría de marcar el paso a la tercera etapa de la trayectoria. Una formulación compartida con Schmucler sobre la tarea de "construir la democracia" puede también ilustrar bien el pensamiento mattelartiano en esta transición:

Tener como mira la democracia redefine la manera de observar las realidades latinoamericanas y la relación que establecen con las experiencias de otros continentes. Si se intenta generar una verdadera teoría crítica de la comunicación que sirva a una práctica igualmente crítica opuesta a los modelos dominantes, deberíamos cruzar experiencias que se desarrollen en distintas partes del mundo (sur-sur, norte-sur), que propicien formas de comunicación democrática, asumirlas como problemáticas comunes - similares y diferentes - y a partir de ellas elaborar conceptualizaciones que nos conduzcan a una formulación teórica. La calidad de la problemática es muchas veces más importante que su localización geográfica. A la internacionalización propiciada por la cultura transnacional, es preciso oponer un nuevo tipo de internacionalismo que borre las viejas huellas de la trasferencia unilateral de modelos teóricos, y que tantas veces nos han encasillado en problemas y soluciones que en realidad eran otra expresión del flujo desigual de la información. Para ello, se vuelve imprescindible recuperar la historia reciente de las experiencias latinoamericanas que trataron o tratan de alentar formas de comunicación popular. Ninguna experiencia futura podrá dejar de tener en cuenta los errores y los aciertos de esta ya larga acumulación histórica que es patrimonio de la cultura popular. La amnesia es mala consejera cuando se trata de construir una teoría crítica. (Mattelart \& Schmucler, 1982, p. 10)

Cuadro 4. Referencias de libros y ediciones de Armand Mattelart publicados en la "tercera etapa" de su trayectoria, y las citas registradas en Google Scholar

\begin{tabular}{lcc}
\multicolumn{1}{c}{ Título, edición, editorial, año de publicación } & $\begin{array}{c}\text { Citas por } \\
\text { idioma }\end{array}$ & $\begin{array}{c}\text { Suma } \\
\text { citas }\end{array}$ \\
\hline Penser les Médias (c/ M. Mattelart, La Découverte, Paris, 19S6) & 314 & $549+$ \\
*Pensar sobre los Medios. Comunicación y Crítica Social (c/ M. \\
Mattelart, Fundesco, Madrid, 19S7; DEI, Costa Rica, 19SS; UAM, \\
México, 19S9; LOM, Santiago, 2000) \\
*Rethinking Media Theory: Signposts and New Directions (c/ M. \\
Mattelart, U. of Minnesota Press, 1992)
\end{tabular}


Cuadro 4. Continuación

\begin{tabular}{|c|c|c|}
\hline Título, edición, editorial, año de publicación & $\begin{array}{l}\text { Citas por } \\
\text { idioma }\end{array}$ & $\begin{array}{c}\text { Suma } \\
\text { citas }\end{array}$ \\
\hline *Pensar as Mídias (c/ M. Mattelart, Loyola, 2004) & + & \\
\hline $\begin{array}{l}\text { Le Carnaval des Images: La Fiction Brésilienne (c/ M. Mattelart, La } \\
\text { Documentation Française, 19\$7) }\end{array}$ & 22 & 448 \\
\hline $\begin{array}{l}\text { *El Carnaval de las Imágenes. La Ficción Brasileña (c/ M. Mattelart, } \\
\text { Akal, Madrid, 19SS) }\end{array}$ & 24 & \\
\hline $\begin{array}{l}\text { *O Carnaval das Imagens: a Ficção na TV (c/ M. Mattelart, } \\
\left.\text { Brasiliense, } 19 S_{9}\right)\end{array}$ & 272 & \\
\hline $\begin{array}{l}\text { *The Carnival of Images: Brazilian Television Fiction (c/ M. Mattelart, } \\
\text { Praeger, 1990) }\end{array}$ & 130 & \\
\hline L'internationale Publicitaire (La Découverte, Paris, 19S9) & 90 & $584+$ \\
\hline *La Internacional publicitaria (Fundesco, Madrid, 19\$9) & 111 & \\
\hline $\begin{array}{l}\text { *Advertising International: The Privatisation of Public Space } \\
\text { (Routledge Comedia, 2017) }\end{array}$ & $3 S_{3}$ & \\
\hline *(Traducción también al turco) & + & \\
\hline La Publicité (La Découverte, Paris, 1990) & 332 & $611+$ \\
\hline *La Publicidad (Paidós, Barcelona, 1990) & 279 & \\
\hline *(Traducciones también al árabe y el turco) & + & \\
\hline $\begin{array}{l}\text { Les Amériques Latines en France (c/ J. Leenhardt, P. Kalfon, M. } \\
\text { Mattelart, Gallimard, Paris, 1992) }\end{array}$ & 20 & 20 \\
\hline $\begin{array}{l}\text { La Communication-monde: Histoire des Idées et des Stratégies (La } \\
\text { Découverte, Paris, 1992) }\end{array}$ & 325 & $1729+$ \\
\hline $\begin{array}{l}\text { *La Comunicación-mundo. Historia de las Ideas y de las Estrategias } \\
\text { (Fundesco, Madrid, 1993; Siglo XXI, México, 1996) }\end{array}$ & 478 & \\
\hline $\begin{array}{l}\text { *Mapping World Communication: War, Progress, Culture (U. of } \\
\text { Minnesota Press, 1994) }\end{array}$ & $40 S$ & \\
\hline $\begin{array}{l}\text { *A Comunicação-mundo: História das Ideias e das Estratégias } \\
\text { (Instituto Piaget, 1996; Vozes, 2010) }\end{array}$ & $51 \mathrm{~S}$ & \\
\hline *(Traducciones también al alemán, el chino, el coreano y el italiano) & + & \\
\hline L'invention de la Communication (La Découverte, Paris, 1994) & 40 & $1146+$ \\
\hline $\begin{array}{l}\text { *La Invención de la Comunicación (Bosch, Barcelona, 1995; Siglo XXI, } \\
\text { México, 1995) }\end{array}$ & $2 S_{5}$ & \\
\hline *The Invention of Communication (U. of Minnesota Press, 1996) & 705 & \\
\hline *A Invenção da Comunicação (Instituto Piaget, 1996) & 116 & \\
\hline *(Traducciones también al árabe, chino e italiano) & + & \\
\hline $\begin{array}{l}\text { Histoire des Théories de la Communication (c/ M. Mattelart, La } \\
\text { Découverte, Paris, 1995) }\end{array}$ & 278 & $3 \cdot 346+$ \\
\hline $\begin{array}{l}\text { *Historia de las Teorías de la Comunicación (c/ M. Mattelart, Paidós, } \\
\text { Barcelona, 1997) }\end{array}$ & 1.411 & \\
\hline $\begin{array}{l}\text { *Theories of Communication: A Short Introduction (c/ M. Mattelart, } \\
\text { Sage, 199S) }\end{array}$ & 333 & \\
\hline *História das Teorias da Comunicação (c/ M. Mattelart, Loyola, 199S) & 1.324 & \\
\hline
\end{tabular}

(continúa...) 
Cuadro 4. Continuación

\begin{tabular}{|c|c|c|}
\hline Título, edición, editorial, año de publicación & $\begin{array}{l}\text { Citas por } \\
\text { idioma }\end{array}$ & $\begin{array}{l}\text { Suma } \\
\text { citas }\end{array}$ \\
\hline $\begin{array}{l}\text { *(Traducciones, además, al árabe, chino, italiano, macedonio, polaco, } \\
\text { rumano, turco, vasco y vietnamés) }\end{array}$ & + & \\
\hline La Mondialisation de la Communication (PUF, Paris, 1996) & 237 & $1.534^{+}$ \\
\hline *La Mundialización de la Comunicación (Paidós, Barcelona, 199\$) & 566 & \\
\hline *Networking the World, 1794-2000 (U. of Minnesota Press, 2000) & 376 & \\
\hline *A Mundialização da Comunicação (Instituto Piaget, 1999) & 34 & \\
\hline *A Globalização da Comunicação (Edusc, 2000) & 321 & \\
\hline *(Traducciones también al árabe, chino, italiano y turco) & + & \\
\hline $\begin{array}{l}\text { L'histoire de L'utopie Planétaire: de la Cité Prophétique a la Societé } \\
\text { Globale (La Découverte, Paris, 1999) }\end{array}$ & 303 & $631+$ \\
\hline $\begin{array}{l}\text { *Historia de la Utopía Planetaria: De la Ciudad Profética a la } \\
\text { Sociedad Global (Paidós, Barcelona, 2000) }\end{array}$ & 326 & \\
\hline $\begin{array}{l}\text { *História da Utopia Planetária: Da Cidade Profética à Sociedade } \\
\text { Global (Sulina, Porto Alegre, 2002) }\end{array}$ & 2 & \\
\hline *(Traducciones también al italiano y al turco) & + & \\
\hline Histoire de la Société de l'information (La Découverte, Paris, 2001) & 373 & $2.354^{+}$ \\
\hline *Historia de la Sociedad de la Información (Paidós, Barcelona, 2002) & 931 & \\
\hline *História da Sociedade da Informação (Loyola, 2002) & 679 & \\
\hline *The Information Society: An Introduction (Sage, 2003) & 371 & \\
\hline $\begin{array}{l}\text { *(Traducciones, además, al alemán, fïlandés, húngaro, italiano, } \\
\text { polaco y turco) }\end{array}$ & + & \\
\hline Geopolítica de la Cultura (LOM, Santiago, 2002; Trilce, Montevideo, 2002) & 134 & 134 \\
\hline Introduction aux Cultural Studies (c/ E. Neveu, La Découverte, Paris, 2003) & 342 & $1.12 S+$ \\
\hline $\begin{array}{l}\text { *Introducción a los Estudios Culturales (c/ E. Neveu, Paidós, } \\
\text { Barcelona, 2004) }\end{array}$ & 271 & \\
\hline *Introdução aos Estudos Culturais (Parábola, 2004) & 515 & \\
\hline *(Traducción también al turco) & + & \\
\hline Diversité Culturelle et Mondialisation (La Découverte, Paris, 2005) & 263 & $6 S_{7+}$ \\
\hline *Diversidad Cultural y Mundialización (Paidós, Barcelona, 2005) & 424 & \\
\hline *Diversidade Cultural e Mundialização (Parábola, 2005) & + & \\
\hline *(Traducciones también, al alemán, árabe y chino) & + & \\
\hline $\begin{array}{l}\text { La Globalisation de la Surveillance: Aux Origines de L’ordre Sécuritaire } \\
\text { (La Découverte, Paris, 2007) }\end{array}$ & 124 & $41 S+$ \\
\hline *Un Mundo Vigilado (Paidós, Barcelona, 2009) & 146 & \\
\hline
\end{tabular}


Cuadro 4. Continuación

\begin{tabular}{|c|c|c|}
\hline Título, edición, editorial, año de publicación & $\begin{array}{l}\text { Citas por } \\
\text { idioma }\end{array}$ & $\begin{array}{l}\text { Suma } \\
\text { citas }\end{array}$ \\
\hline *The Globalization of Surveillance (Polity Press, 2010) & $14 \mathrm{~S}$ & \\
\hline *(Traducciones, también, al árabe, coreano, turco) & + & \\
\hline $\begin{array}{l}\text { Pour un Regard-monde: Entretiens avec Michel Sénécal (La Découverte, } \\
\text { Paris, 2011; Université de Montréal, 2011) }\end{array}$ & 16 & 44 \\
\hline $\begin{array}{l}\text { *Por una Mirada-mundo: Conversaciones con Michel Sénécal (U. de } \\
\text { la Frontera, Chile, 2013; Gedisa, Barcelona, 2014) }\end{array}$ & $2 S$ & \\
\hline $\begin{array}{l}\text { Le Profilage des Populations, Du Livret Ouvrier au cybercontrôle } \\
\text { (c/ A. Vitalis, La Découverte, 2014) }\end{array}$ & 65 & 124 \\
\hline *De Orwell al Cibercontrol (c/ A. Vitalis, Gedisa, Barcelona, 2015) & 59 & \\
\hline$F=3.144|E=5.593| I=2.969 \mid P=3.7 S 1$ & & $15.487+$ \\
\hline
\end{tabular}

\section{CONSIDERACIONES (SEMI)FINALES DE LA META-INVESTIGACIÓN SOBRE LA INFLUENCIA DE MATTELART}

Armand Mattelart fue uno de los primeros, y seguramente el más importante, de los investigadores que desde América Latina plantearon los problemas de la transnacionalización de la cultura y la comunicación, no solo en los medios masivos, sino también en la tecnología, el entretenimiento y el turismo, en la industria publicitaria, mercadotécnica y de la investigación "comercial", en la electrónica "pesada", las tecnologías espaciales, la educación, la política, la propaganda y el espionaje. No obstante, las deformaciones que sus trabajos han ido sufriendo a lo largo de cinco décadas en la amplísima difusión que evidencian los datos recabados, Mattelart no dejó nunca de advertir las necesarias reservas críticas que, aunque han estado presentes desde el principio, tienen una formulación más acabada en obras más recientes.

Para Maldonado (2019), ese "conjunto de lógicas y acciones que constituyen la praxis del pensamiento crítico" se pusieron en evidencia en un libro que no está entre los más citados de los Mattelart, pero que quizá sea el más importante: Pensar Sobre los Medios: Comunicación y Crítica Social (1987). Este libro "representa un avance epistemológico notable, porque vuelve más denso su marco teórico; porque ilumina nuevos aspectos de investigación y reformula cuestiones investigadas con anterioridad, profundizando el conocimiento acerca de los modelos utilizados y diseñando caminos metodológicos innovadores" (Maldonado, 2019, p. 54), como es el caso, "paradigmático, de su línea de investigación histórica-genealógica de la formación de las teorías de la comunicación” (Maldonado, 2019, p. 54).

También llama la atención que, hacia el final de su larga entrevista con Sénécal (2013), Mattelart sintetice su postura ante lo que llama la tensión 
"saber/poder" de la siguiente manera antes de dedicarse al análisis de los mecanismos de vigilancia y control:

He pasado de un cuestionamiento de una forma de monopolio cognitivo, según la expresión creada por el canadiense Harold Innis, constituido por el dispositivo mediático y las industrias culturales, a otra forma de monopolio cognitivo: el de las industrias del conocimiento. Esta cuestión adquiere una importancia fundamental, en este momento de la historia, en el que nuestras sociedades se sitúan en el punto de inflexión hacia una sociedad y una economía en las que los recursos inmateriales están en la base de toda actividad. A diferencia de la sociedad de la información, asentada sobre el pragmatismo a corto plazo, la sociedad del saber supone pesar el futuro del mundo a partir de la historia y de la memoria colectiva. El reto que se nos presenta es el de impedir que el futuro cognitivo sea un calco de los esquemas de saber/poder y de las jerarquías que han lastrado a la sociedad industrial, en su huida hacia delante, buscando el progreso infinito. (Mattelart \& Sénécal, 2013, p. 239)

Los acontecimientos de la última década en el mundo al mismo tiempo que han ahondado las tendencias bien analizadas e interpretadas por Mattelart en la evolución del capitalismo, aparentemente, han alejado más su confianza en los mecanismos académicos institucionalizados, con los que siempre se ha mostrado muy crítico. Sin embargo, de acuerdo con la información recabada y analizada como ha sido inicialmente presentada hasta aquí, la influencia y el reconocimiento de Mattelart no solo se han mantenido a lo largo de una trayectoria de más de cinco décadas en el campo de estudio de la comunicación, en Latinoamérica y más allá, sino que han crecido considerablemente en su etapa más reciente. Como resultado representativo, puede señalarse, de manera sintética en el Cuadro 5, el listado de sus cinco títulos más citados.

Cuadro 5. Los cinco títulos más citados de Armand Mattelart (en Google Scholar) Título, autoría, editorial, año de la edición original

Para Leer al Pato Donald: Comunicación de masa y colonialismo (c/ A. Dorfman, Ed. Universitarias, Valparaíso, 1971)

La Communication-monde: Histoire des Idées et des Stratégies (La Découverte, Paris, 1992) 
Ninguna de las cinco obras es particularmente reciente. Apenas una fue publicada al inicio del siglo XXI, y con la excepción de Para Leer al Pato Donald, que es de 1971, las otras cuatro fueron editadas originalmente en francés y contienen una perspectiva de historización de las prácticas, los sistemas y los saberes de la comunicación, lo que quizá merecería la atención central de otro análisis. Pues aunque la historización ha sido una constante en el discurso de Mattelart a partir quizá de Pensar Sobre los Medios (1987), el reconocimiento de los lectores expresado en la cantidad de citas puede llegar a ser sorprendente para más de alguno. Y probablemente pueda enriquecerse el análisis con el recurso a métodos de procesamiento de datos como el $A R S$ (análisis de redes sociales), empleado por los mexicanos García-Macías y Fortanell (2018) en otro trabajo que documenta la influencia de Mattelart, esta vez en un gran corpus de artículos contenidos en el SciELO Citation Index (https:/bit.ly/3qLiLIZ), en un rango de fechas de publicación entre 1997 y 2017.

El corpus de análisis . . consiste de 936 artículos publicados en 16 fuentes distintas, en los que participan un total de 1.175 autores que pertenecen a 404 organizaciones de 31 países. 774 de estos textos (82,7\%) son en español, 124 en portugués, 35 en inglés y 3 en francés. Los registros incluyen 20.573 referencias bibliográficas, 15.199 fuentes y 13.376 primeros autores citados, además de 2.610 palabras clave descriptoras. Estos datos se analizaron con el objetivo de identificar, graficar y describir redes (1) de colaboración; (2) de citaciones entre publicaciones; y (3) conceptuales. (García-Macías \& Fortanell, 2018, p. 124)

Sin entrar en más detalle, los resultados "provisionales” de García-Macías y Fortanell (2018) permiten "abrir procesos reflexivos más amplios sobre los posicionamientos autor-tradiciones-campo", mediante la identificación de seis “clusters" (conjuntos de nodos cercanamente relacionados de manera estadística), en los cuales se agrupan los autores referidos veinte veces o más en el corpus. Estos clusters fueron preliminarmente etiquetados como "1. teorías sociales en comunicación”; "2. estudios de audiencias, recepción, consumo cultural, prácticas”; “3. pensamiento comunicacional latinoamericano”; "4. pensamiento sobre representación, mayoritariamente europeo"; "5. Agenda, noticia discurso, sociedad red"; $y$ “6. teorías sobre prácticas digitales emergentes". También compusieron "seis rankings de autores conforme a diversas medidas calculadas a partir de una red de cocitaciones ... comparando el número de citas directas recibidas con los indicadores estructurales de centralidad (de grado, intermediación y cercanía)" (pp. 124-128). 
Así, catorce autores están presentes en los seis rankings analizados. Jesús MartínBarbero y Manuel Castells mantienen las posiciones uno y dos en todas las dimensiones ... Doce autores más son constantes en los seis rankings, si bien con determinadas variantes en el orden de sus posiciones: Pierre Bourdieu, Umberto Eco, Michel Foucault, Raúl Fuentes-Navarro, Néstor García Canclini, Jürgen Habermas, Stuart Hall, Henry Jenkins, Armand Mattelart, Marshall McLuhan, Carlos Alberto Scolari y Eliseo Verón. (García-Macías \& Fortanell, 2018, p. 131)

Cabe señalar que Mattelart ocupa el tercer sitio en cuatro de los seis rankings, muy cerca de los dos "punteros" Martín-Barbero y Castells, además de que llama la atención que seis de los 14 autores señalados hayan fallecido ya (Bourdieu, Eco, Foucault, Hall, McLuhan y Verón), que no haya ninguna mujer en la lista y que solamente tres trabajen en América Latina. Como concluyen los autores de ese artículo sobre un proyecto que está aún en proceso, el empleo de métodos interpretativos como el análisis de redes, "por una parte, confirma la dispersión del campo de la comunicación", especialmente en sus temáticas, pero, por otra parte, "al visibilizar las series de vínculos que conforman la estructura del campo ... permite apreciar con claridad la influencia de tradiciones teóricas muy bien identificadas en la producción científica y, por lo tanto, en el propio campo", que ellos insisten en llamar "un mundo pequeño" (García-Macías \& Fortanell, 2018, p. 136).

La influencia de la obra de Armand Mattelart sobre la conformación y evolución de ese "mundo", de ese campo académico, permanece entre las más constantes y quizá, determinantes de ciertas orientaciones y sesgos característicos. Puede sostenerse que los libros de ese autor pueden "defenderse" muy bien a sí mismos y por ende a su autor, pues en palabras de Roseli Figaro (2019), invitan a "pensar teórica y metodológicamente a contrapelo de los postulados funcionalistas y positivistas" y mediante esa reflexión a "entender la comunicación como un proceso de interacción social, mediado por las fuerzas que actúan en la cultura y en la política" (p. 194). M

\section{REFERENCIAS}

Bourdieu, P. (1993). The field of cultural production. Columbia University Press. Bourdieu, P. (2000). Los usos sociales de la ciencia. Nueva Visión.

Chaffee, S. H., Gómez-Palacio, C., \& Rogers, E. M. (1990). Mass communication research in Latin America: Views from here and there. Journalism Quarterly, 67(4), 1015-1024. https://doi.org/10.1177/107769909006700402 
Constantinou, C. M. (2008). Communications/excommunications: An interview with Armand Mattelart. Cultures and Politics of Global Communication, 34(S1), 21-42. https://doi.org/10.1017/S0260210508007766

Crane, D. (1972). Invisible colleges: Diffusion of knowledge in scientific communities. The University of Chicago Press.

Cruz-Quintana, F. (2019). Conglomerados editoriales y tecnológicos: La industria del libro en la encrucijada. In F. Toussaint \& F. Sierra (Coords.), Economía politica y medios digitales (pp. 157-171). Comunicación Social.

del Valle Rojas, C. (2013). Presentación a la edición chilena. In A. Mattelart, Por una mirada-mundo. Conversaciones con Michel Sénécal (pp. 11-14). Universidad de la Frontera.

Eco, U. (1992). El nombre de la rosa. RBA Editores. (Obra original publicada en 1983)

Figaro, R. (2019). Pensar a contrapelo: Mattelart e a pesquisa em Comunicação. In A. E. Maldonado \& E. León-Castro (Eds.), Investigación crítica de la comunicación en América Latina: diálogos con la vertiente Mattelart (pp. 193-209). Ciespal.

Fuentes-Navarro, R. (2018). La ciencia y la cultura como objetos de comunicación y práctica. In S. Herrera \& C. E. Orozco (Coords.), Comunicar ciencia en México. Prácticas y escenarios (pp. 15-41). Iteso.

Fuentes-Navarro, R. (2019). Tres legados metodológicos para la historia de la investigación de la comunicación en América Latina. Revista Latinoamericana de Ciencias de la Comunicación, (32), 40-46.

Fyfe, A., Coate, K., Curry, S., Lawson, S., Moxham, N., \& Røstvi, C. M. (2017). Untangling academic publishing: A history of the relationship between commercial interests, academic prestige and the circulation of research. Zenodo. https://doi.org/10.5281/zenodo.546100

García-Macías, A., \& Fortanell Trejo, B. (2018). El "mundo pequeño" de la comunicación en América Latina. Un análisis de redes sociales desde los artículos científicos de la disciplina en el Scielo Citation Index. Revista Latinoamericana de Ciencias de la Comunicación, (28), 120-137.

Giménez-Toledo, E., Tejada-Artigas, C. M., \& Oliveira, A. B. (2019). El libro y las editoriales académicas según los investigadores brasileños de Ciencias Sociales y Humanidades. El profesional de la información, 28(6), 1-13. https://doi.org/10.3145/epi.2019.nov.03

Gómez-Palacio, C. (1989). The origins and growth of mass communication research in Latin America [Tesis doctoral inédita]. Stanford University.

Infoamerica. (s.d.). Armand Mattelart: perfil biográfico y académico. Recuperado em 30 de agosto, 2020, de https://bit.ly/3a3eIlJ 
Kuhn, T. S. (1962). The structure of scientific revolutions. The University of Chicago Press.

Kulczycki, E., Engels, T. C. E., Pölönen, J., Bruun, K., Dušková, M., Guns, R., Nowotniak, R., Petr, M., Sivertsen, G., Starčič, A. I., \& Zuccala, A. (2018). Publication patterns in the social sciences and humanities: evidence from eight European countries. Scientometrics, 116, 463-486. https://doi.org/10.1007/s11192-018-2711-0

Maldonado, A. E. (2019). Trilhas históricas da vertente teórica Mattelart na América Latina. In A. E. Maldonado \& E. León-Castro (Eds.), Investigación crítica de la comunicación en América Latina: Diálogos con la vertiente Mattelart (pp. 31-70). Ciespal.

Maldonado, A. E., \& León-Castro, E. (Eds.). (2019). Investigación crítica de la comunicación en América Latina: Diálogos con la vertiente Mattelart. Ciespal.

Mattelart, A. (1978). Notas al margen del imperialismo cultural. Comunicación y Cultura, (5), 7-27. https://bit.ly/3a1tp8E

Mattelart, A. (2013). Por una mirada-mundo: Conversaciones con Michel Sénécal. Universidad de la Frontera.

Mattelart, A., \& Dorfman, A. (1972). Para leer al Pato Donald: Comunicación de masa y colonialismo. Siglo XXI.

Mattelart, A., \& Mattelart, M. (1987). Pensar sobre los medios: Comunicación y crítica social. Fundesco.

Mattelart, A., \& Mattelart, M. (1997). Historia de las teorías de la comunicación. Paidós.

Mattelart, A., \& Schmucler, H. (1982). Construir la democracia. Comunicación $y$ Cultura, (7), 7-10. https://bit.ly/379swsX

Schwarz, C., \& Jaramillo, O. (1986). Hispanic American critical communication research in its historical context. In R. Atwood \& E. G. McAnany (Eds.), Communication and Latin American society: Trends in critical research, 1960-1985 (pp. 48-75). The University of Wisconsin Press.

Tejada-Artigas, C.-M., Giménez-Toledo, E., \& Oliveira, A. B. (2020). El prestigio delas editoriales académicas con libros en Ciencias Sociales y Humanidades en Brasil. Transinformação, 32, 1-13. https://doi.org/10.1590/2318-0889202032e190043

Thompson, J. B. (2005). Books in the digital age: The transformation of academic and higher education publishing in Britain and the United States. Polity.

Zarowsky, M. (2013). Del laboratorio chileno a la comunicación-mundo: Un itinerario intelectual de Armand Mattelart. Biblios.

Artículo recibido el 29 de septiembre y aprobado el 6 de diciembre de 2020. 